\title{
THE EFFECT OF MAGNETIC FIELD VARIATIONS IN A MIXTURE OF COCONUT OIL AND JATROPHA ON FLAME STABILITY AND CHARACTERISTICS ON THE PREMIXED COMBUSTION
}

\author{
Dony Perdana $\bowtie$ \\ Department of Mechanical Engineering ${ }^{l}$ \\ dony_perdana@yahoo.co.id \\ Satworo Adiwidodo \\ Department of Mechanical Engineering \\ State Polytechnic of Malang \\ 9 Jl. Soekarno-Hatta, Malang, East-Java, Indonesia, 65141 \\ Mochamad Choifin \\ Department of Mechanical Engineering ${ }^{l}$ \\ Wigo Ardi Winarko \\ Department of Mechanical Engineering \\ University of Jember \\ $37 \mathrm{Jl}$. Kalimantan, Jember, East-Java, Indonesia, 68121 \\ ${ }^{1}$ Universitas Maarif Hasyim Latif \\ $30 \mathrm{Jl}$. Ngelom Megare, Taman, Sidoarjo, East-Java, Indonesia, 61257
}

$\triangle$ Corresponding author

\begin{abstract}
This study investigates the effect of attracting and repels magnetic fields with the materials of vegetable oil in the form of a mixture of coconut oil and jatropha (B50) against the behavior of stability and characteristics of flame in the process of premixed burning. The fuel for a mixture of vegetable oil of $600 \mathrm{ml}$ was filled into the boiler heated with a gas stove to be evaporated at a temperature of $300{ }^{\circ} \mathrm{C}$ and 3 bar pressure was kept constant was mixed with air from the compressor in the burner room. Then a flame was ignited at the end of the nozzle to form a diffusion flame, the flame formed was then given north (N) and south (S). The results showed that the flame speed of the attractive magnetic field was $52.22 \mathrm{~cm} / \mathrm{sec}$, the repulsive magnetic field was $50.49 \mathrm{~cm} / \mathrm{sec}$ while without a magnetic field was $49.79 \mathrm{~cm} / \mathrm{sec}$. The increase in the laminar flame speed in the attractive magnetic field is caused by the electron spin becoming more energetic and due to the change in the spin of the hydrogen proton from para to ortho. The attractive magnetic field has the strongest effect on increasing the flame speed. This makes the flame more stable in the equivalency ratio range of 0.75-1.17 compared to without a magnetic field in the same equivalency ratio range. This was so because $\mathrm{O}_{2}$ where it is in nature of paramagnetic was pumped more crossing the flame from south to north poles whereas the heat brought by $\mathrm{H}_{2} \mathrm{O}$ in nature of diamagnetic was pumped more crossing north to south poles. Whereas on the repel magnetic field, it was hotter when brought by $\mathrm{H}_{2} \mathrm{O}$ pumped into the flame whereas $\mathrm{O}_{2}$ tended to be pumped going out of the flame. This caused the combustion in the flame was smaller and the reaction was not maximum. As a consequence, the laminar flame speed was more lacking and the reaction was not to the fullest. As a consequence, the laminar flame speed in the repel was fewer than the attract magnetic field.
\end{abstract}

Keywords: vegetable oil, premix combustion, magnetic field, flame stability, flame characteristics, flame shape, combustion process, laminar flame speed, equivalence ratio, attract magnetic field.

DOI: $10.21303 / 2461-4262.2021 .001996$

\section{Introduction}

The increasing environmental threat due to exhaust gas emissions, the problem of global warming, and the threat of instability in fuel supply have had a bad impact on developing countries, especially oil-importing countries. Several researchers have found alternative fuels for internal combustion engines as well as developing various vegetable oils from various plants, such as 
jatropha [1], soybean [2], radish [3], algae [4], and canola [5]. Many studies have shown that fuels have the main properties impacting the performance of diesel engines [6, 7]. Studies have shown that the combustion behavior of vegetable oil is similar to that of diesel oil [8]. Using sunflower, cottonseed (CSO), corn, and olive oil on blend diesel fuel in the bus engine, it is shown that the brake thermal efficiency and brake specific fuel consumption is almost the same as diesel fuel. The mixture of $60 \% \mathrm{CSO}$ and $40 \%$ diesel which is preheated to $90{ }^{\circ} \mathrm{C}$ brake thermal efficiency, ignition delay, and heat release is close to that of diesel fuel [9]. Compression ignition engine fueled with cottonseed oil and its blends with diesel fuel found that brake thermal efficiency, $\mathrm{CO}_{2}$ and CSO100 peak cylinder pressure were almost the same as diesel at all loads [8-10]. However, each vegetable oil has different characteristics and behavior, this is due to its specific physical and chemical properties. Also, the formation of the precipitate and the piston sticks to long-term use due to the presence of oxygen in the molecule and the reactivity of the unsaturated hydrocarbon chains causing problems in the use of vegetable oils [11]. There are also several problems encountered in its use. Such as clogged filters, injectors, pumps, and deposits on the piston rings in the combustion chamber [12]. However, various solutions were proposed to overcome these problems, among others:

- mixing vegetable oil with diesel oil in different proportions;

- heating vegetable oil;

- exhaust gas recirculation;

- modify the combustion chamber (piston, injector, etc.).

Research using Karanja methyl ester (KME)-diesel oil blends fuel (KME 5, 10, 15, 20, 30, $40,50,100)$ shows that mechanical efficiency achieved with KME30 is higher than diesel at lower loading conditions and emission characteristics are higher than pure diesel but the KME30 has relatively better performance concerning other blends [13]. Another researcher examined the performance of Karanja oil with diesel blends (non-preheated blend and preheated blend) was studied in comparison with diesel fuel by increasing the initial fuel temperature variation from $35-80{ }^{\circ} \mathrm{C}$. The results showed that the emission values of hydrocarbon and nitric oxide were decreased and the carbon-monoxide value was increased for the above-said blend when compared with the diesel fuel operation [14]. Other researchers mixing rapeseed oil with diesel oil showed that at high engine loads, the start of combustion for the blends was slightly earlier than that for diesel fuel, but the peak cylinder pressure and heat release rate were identical and the BSFC of rapeseed oil-diesel blends were higher than that of diesel fuel under all range of engine loads, but the BSEC was improved at high engine loads [13-15]. Alternative fuels such as waste cooking oil (WCO)-based biodiesel were blended with the B10 and B20 found that using B10 and B20 as fuels can decrease these emission factors in the range of $17-52 \%$ and $49-73 \%$ on a mass basis, as well as $21-61 \%$ and $61-83 \%$ on a toxicity basis [16]. Research with variations in fossil fuel diesel (B0), $20 \%$ rapeseed methyl ester in fossil diesel (B20), and pure rapeseed methyl ester (B100) result in the effect was weaker for B0 low SAPS in comparison with high SAPS, while B100 high SAPS leads to increasing the oxidative stress in comparison with B20 high SAPS, thus indicating the role of biofuel composition which may be associated with bio micro markers found for biofuel exhausts as well with higher oxidation and nitrification of the biofuel particle surface, relating with higher reactivity and oxidation behavior [17]. Other researchers used a mixture of conventional diesel oil with biodiesel from microalgae. The fuel blends - B2 (2 \% microalgae biodiesel $+98 \%$ conventional diesel) showed the $\mathrm{HC}$ emissions from B2 decreased by $50.2 \%$ [16-18]. A mixture of $30 \%$ vegetable oil and $70 \%$ diesel fuel can be burned in a CI engine without the need for engine modifications or fuel preheating [19].

Along with continuous improvements in the combustion system, new concepts for the combustion system are required to be investigated. Combustion assisted by magnetic fields can be a viable option in increasing combustion efficiency and flame control. Magnetic fields have been known to influence the flame behavior and flow of gases due to the paramagnetic and diamagnetic properties of the constituent gases. In diffusion flame, $\mathrm{HC}, \mathrm{H}_{2} \mathrm{O}, \mathrm{N}$, and $\mathrm{CO}_{2}$ are diamagnetic while oxygen is the main paramagnetic gas. Because the paramagnetic susceptibility to oxygen is greater, the diamagnetic behavior is considered negligible. Gases that contain more $\mathrm{O}_{2}$, such as air, tend to move towards stronger magnetic fields and gases with less $\mathrm{O}_{2}$ such as fuel or combustion gases tend 
to move towards weaker magnetic fields. Based on this, it is possible to use a magnetic field to control the flow field in the combustion area to improve the combustion characteristics. Hydrocarbon fuel molecules treated with a magnetic field tend to break down, creating smaller particles resulting in better combustion [20]. The hydrogen particles in fuels are arranged in two forms of para and ortho isomers. Hydrogen effectively describes efficient combustion. In the state of para spinning from one atom relative to another is in the opposite direction, whereas in the ortho form the rotation of one atom relative to another is in the same direction. When a strong magnet is applied to the fuel, the hydrocarbons change orientation and change from a para form to an ortho form [20]. The ortho forms a sizeable reduction in the inter-molecular force which occurs causing an increase in the space between the hydrogens. Because the magnetic treatment causes the fuel-oxygen relationship to increase, resulting in complete fuel combustion in the combustion chamber [21]. The $\mathrm{CO}$ and $\mathrm{HC}$ content values decreased by $90 \%$, and $58 \%$, respectively, when using a 2000 gauss magnetic field in a four-stroke single-cylinder diesel engine [22]. Two-stroke single-cylinder diesel engines and added a magnetic field with an intensity of 2000-9000 gauss resulted in a $40 \%$ reduction in $\mathrm{CO}$ and $30 \% \mathrm{HC}[20]$. The use of a 5000-gauss magnetic field achieves a reduction in $\mathrm{HC}$ and $\mathrm{CO}$ emissions of $12 \%, 22 \%$, and $7 \%$ in fuel consumption, respectively, but increases in $\mathrm{NO}_{\mathrm{X}}$ and $\mathrm{CO}_{2} 19 \%$ and $7 \%$, respectively [23]. The magnetic field intensity of 2000-9000 gauss resulted in a reduction of $\mathrm{CO}$ and $\mathrm{HC}$ by $30 \%$ and $40 \%$, respectively, the fuel consumption of 9-14\%, proportional to the strength of the magnet, while $\mathrm{CO}_{2}$ increased by $10 \%$ [20]. From all of these studies, combustion stability which is critical to engine performance has not been discussed. Therefore, further research is needed, especially regarding the effect of magnetic fields in stabilizing the combustion process. This study provides data on the stability of combustion in a magnetic field which greatly supports the combustion process of vegetable oil in the engine to be more efficient. Very few researchers have conducted research on premixed combustion with mixed fuel between vegetable oils which is influenced by magnetic fields. The stability of premixed flames in high velocity flows has been an important topic of investigation in combustion research over the past few decades. The application of flame stability is useful in the combustion of military aircraft, gas turbines. Industrial furnaces and industrial oil burners. Particular attention is paid to the research of alternative fuels that are affected by magnetic fields. In other words, it is necessary to study the effect of these fuels on combustion, especially on industrial oil burner equipment during long-term use. Therefore, this study aims to provide a discussion about the effect of magnetic field strength which is varied by repulsion and attraction and without magnetic fields on the behavior stability and characteristics of the flame in the combustion process. But further research is needed especially for efficient high thermal energy radiation production, combustion characteristics, and flame stability. The present work provides the data for the efficient and stable operation of military aircraft, gas turbines. Industrial furnaces and industrial oil burners using vegetable oil and orientation magnetic filed.

\section{Materials and methods}

Vegetable oils tested include coconut oil and jatropha. All vegetable oils were obtained from commercial products. The fatty acid composition, physical properties, chemical properties, glycerol, gum, and water of vegetable oils have been shown in our previous research [24].

\section{1. Experimental equipment scheme}

The experimental equipment is shown schematically in Fig. 1. The fuel for a mixture of coconut oil and jatropha B50 of $600 \mathrm{ml}$ was filled into the boiler, then heated with a gas stove to be evaporated at a temperature of $300{ }^{\circ} \mathrm{C}$, and the 3 bar pressure was kept constant. The fuel inlet valve was opened and the air inlet valve was closed. The next process was the air inlet valve was opened slightly and the height difference is recorded in the flow control. The altitude differences in the fuel flow control are recorded and kept constant.

By increasing the opening of the air inlet valve gradually, every height difference in the airflow control was recorded. Vegetable oil vapor B50 mixture from the boiler was mixed with air from the compressor in the burner room. The reactant mixture then flew into a nozzle with 
an inner diameter of $6 \mathrm{~mm}$, then a flame was ignited at the end of the nozzle to form a diffusion flame. By increasing the amount of air in the mixture the flame will gradually change to a premixed flame.

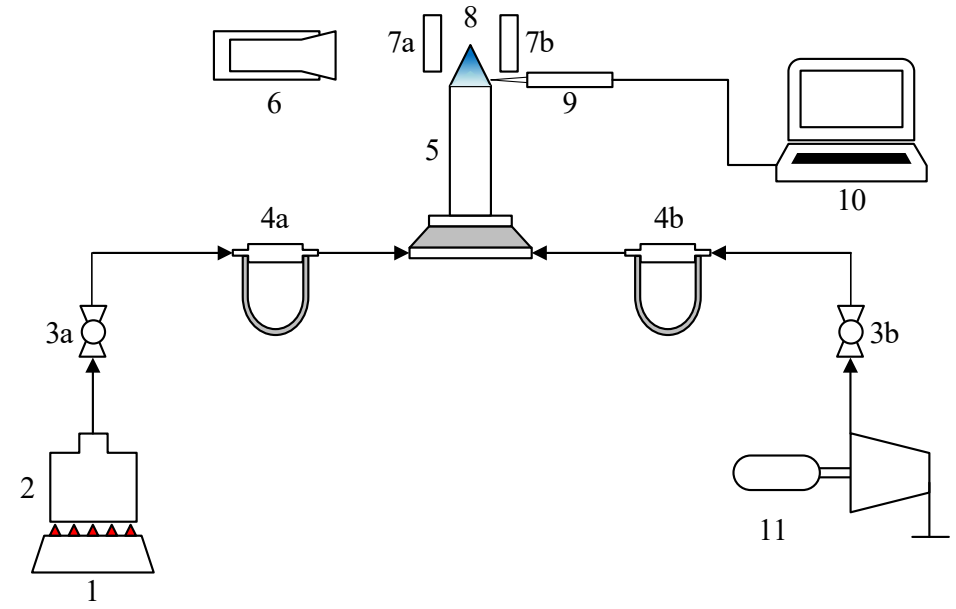

Fig. 1. Experimental apparatus:

1 - stove; 2 - boiler; 3 - valve; 4 - flow control; 5 - burner type cylinder; 6 - high speed camera;

7 - magnet permanent; 8 - flame; 9 - thermocouple; 10 -data logger; 11 - compressor

\section{2. Thermocouple positions}

In the gap between the two magnets which was $12 \mathrm{~mm}$ apart was placed a burner with a diameter of $6 \mathrm{~mm}$ and a length of $200 \mathrm{~mm}$ made of stainless steel pipe. The image of the premixed flame formed at the nozzle's mouth was recorded until the flame went out using a high-speed camera with a speed of $320 \mathrm{fps}$.

Thermocouple type $K$ was connected to the data logger to record the measured temperature by placing the sensor in the reaction zone position $2 \mathrm{~mm}$ above the burner tip in Fig. 2.

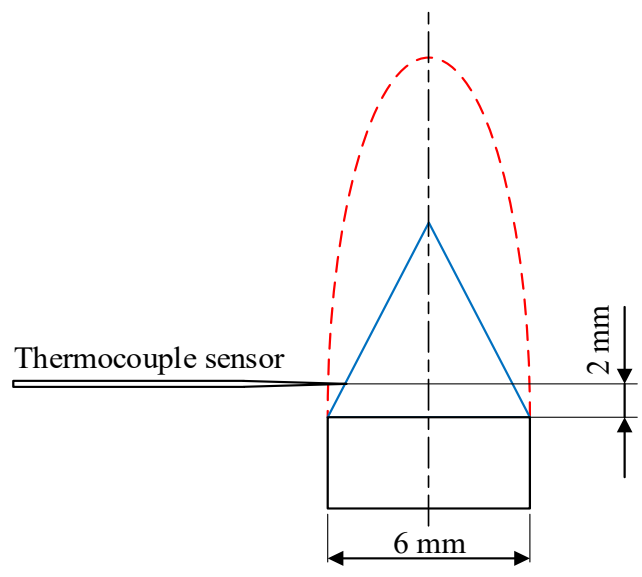

Fig. 2. Thermocouple positions

\section{3. Magnetic field orientation setting}

The flame formed was then given north $(\mathrm{N})$ and south $(\mathrm{S})$ with varying orientations in two conditions, namely the magnetic field of attraction and repulsion as shown in Fig. 3.

The magnet was made of a permanent magnet bar with nickel-plated grade N45 neodymium with a magnetic field intensity of $1.1 T$ (11000 gausses) with dimensions of $40 \times 25 \times 10 \mathrm{~mm}$.

The magnetic bar was placed on a holder made of aluminum plate and tightened by bolts and nuts so that it can be removed and reassembled to change the direction of the magnetic fields attract (S-N) and repel (N-N) (Fig. 3). 


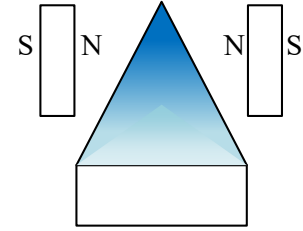

$a$

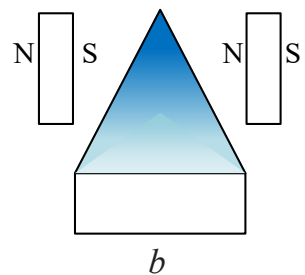

Fig. 3. The orientation of the magnetic field: $a$-repulsive; $b$-attractive

\section{Results}

3. 1. The stability and characteristics of the flame at various equivalence ratios and magnetic field directions

Fig. $4, \boldsymbol{a}-\boldsymbol{c}$ shows the premixed flame of the coconut oil and mixture of jatropha B50, respectively. An attractive magnetic field may burn at a poorer equivalence ratio than a magnetic field repels or without a magnetic field. The premixed flames of the attractive magnetic field experience lift-off then blew off at an equivalence ratio below 0.75 while the premixed flames of the magnetic field repel or without magnetic field did not experience lift-off then blow off below 0.83 . This shows that the magnetic field repels and without more difficult to evaporate than the attractive magnetic field, giving the attractive magnetic field to the flame as a whole increase the combustion reaction which can be seen from the thinner reaction zone and the shorter flame. Giving an attractive magnetic field to the flame, making the flame brighter, indicating that the magnetic field made the electron spin more energetic, while the proton spin changed from para to ortho then the bonds between $H$ atoms in vegetable oil were stretched and combustion occurred, the reaction became more intense.

It can be seen from Fig. $4, c$ that the reaction zone in the flame in the attractive magnetic field was thicker than the reaction zone in the flame, the magnetic field is both repulsive and without.

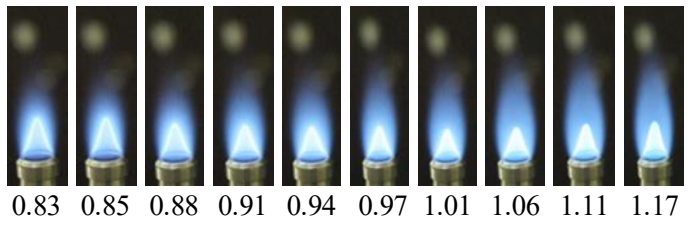

a

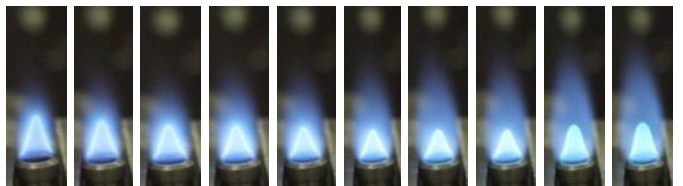

$\begin{array}{llllllllll}0.83 & 0.85 & 0.88 & 0.91 & 0.94 & 0.97 & 1.01 & 1.06 & 1.11 & 1.17\end{array}$ b

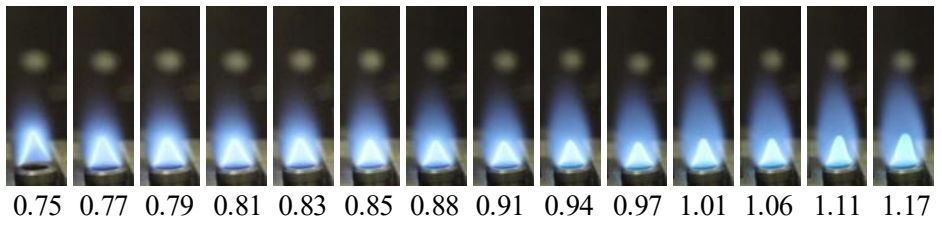

$c$

Fig. 4. Stability and flame shape of the vegetable oil B50 mixture to its equivalence ratio: $a$-without a magnetic field; $b$ - repulsive magnetic field; $c$ - attractive magnetic field

This is because the diffusion rate of the fuel in the flame of the attractive magnetic field is faster than the reaction speed. This happens because the fuel molecules are freer to move. On the other hand, the magnetic field repels, and without a magnetic field doesn't move because it is more difficult to move because the molecular attraction is stronger so that the reaction speed is faster. The magnetic field repels and without a magnetic field does not change the stability of the flame. From the flame image, it can be seen that in the without of a magnetic field (Fig. 4, a) the flame became more transparent, while in the magnetic field it repels and attracts attraction (Fig. $4, \boldsymbol{b}, \boldsymbol{c}$ ) the flame is thicker. This happens because paramagnetic oxygen will move in the direction of the field while the $\mathrm{H}_{2} \mathrm{O}$ product which carries heat is diamagnetic which tends to move against the direction of the magnetic field line (Fig. 8). In the magnetic field repels or without magnetic field come out of the pole thus it pushes $\mathrm{O}_{2}$ into the flame, while $\mathrm{H}_{2} \mathrm{O}$ which is the heat source is pulled out of the flame. On the other hand, in the attractive magnetic field (Fig. 4, c) the magnetic field lines entered the magnet thus $\mathrm{O}_{2}$ was pulled out of the flame while $\mathrm{H}_{2} \mathrm{O}$ as a heat source 
was pushed into the flame (Fig. 8). These two events made chemical reactions not optimal. The direction of the attractive magnetic field gave a stronger effect. The flames became more stable towards the poorer equivalent ratio, from 0.83 to 0.75 . Also, the seconder flame became thinner, which indicates that the combustion reaction in the reaction zone got stronger. This happens because $\mathrm{O}_{2}$ was pumped across the flame from the pole of the attractive magnetic field while $\mathrm{H}_{2} \mathrm{O}$ as a heat source was pumped across the flame. This cross transport of heat and mass made the maximum reaction. directions

\section{2. The premixed combustion speed at various equivalence ratios and magnetic field}

Fig. 5 shows the laminar flame velocity of the coconut oil and jatropha B50 mixed estimated from Fig. 4. The maximum laminar flame velocity at the equivalence ratio was about slightly over unity. The maximum flame velocity of the attractive magnetic field occurred in a mixture richer than a magnetic field repels or without a magnetic field. The speed of the laminar flame decreased as the fuel-air mixture gets richer or poorer. The application of a magnetic field causes the speed of a laminar flame to increase as the electrons become more energetic. The magnetic field makes the laminar flame velocity increase more rapidly in the area of the poor mixture and tends to be more stable towards poorer combustion at the repelling magnetic pole.

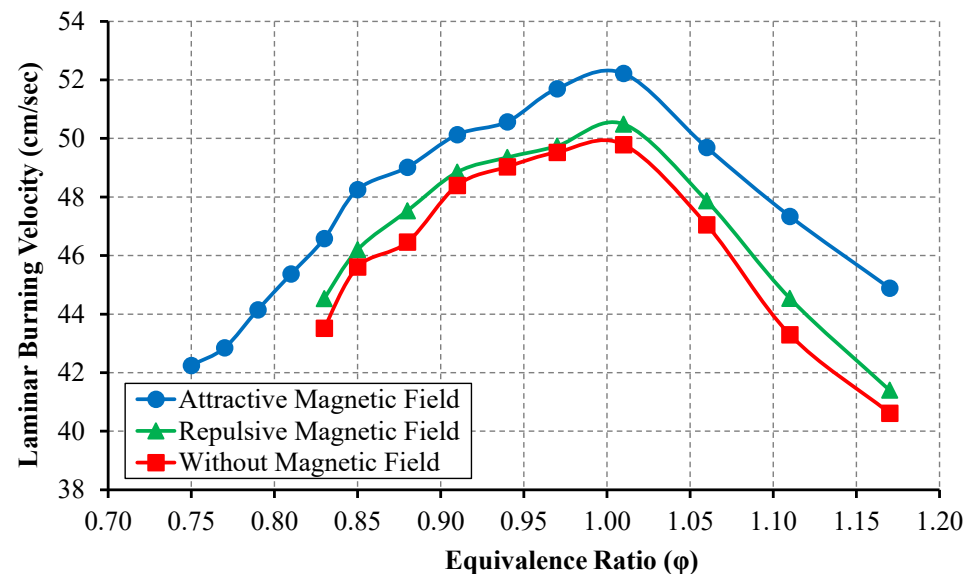

Fig. 5. The laminar combustion rate of the vegetable oil B50 mixture toward its equivalence ratio at various magnetic field orientations and without a magnetic field

This shows that the magnetic field helps pump out paramagnetic oxygen and controls the heat carried by more diamagnetic $\mathrm{H}_{2} \mathrm{O}$ to the flame. Different magnetic fields have different effects on the speed of combustion. As previously explained, the repulsive magnetic field gives less effect than the attractive magnetic field. The attractive magnetic field produces a higher flame velocity because it pumps more heat that is carried by $\mathrm{H}_{2} \mathrm{O}$ to the flame (Fig. 8). As a result, the combustion reaction becomes faster in the attractive magnetic field.

\section{3. The temperature at various equivalence ratios and direction of a magnetic field}

Fig. 6 shows the flame temperature of the premixed combustion of the coconut oil mixture and jatropha B50. It can be seen that the trend of temperature change with the equivalence ratio follows the trend of changes in the speed of the laminar flame. Because the speed of the flame states the speed of the combustion reaction, namely the speed of heat release. Even though the magnetic field increases the temperature of the flame, a higher increase in flame velocity in the absence of magnetic field results in a lower increase in temperature.

This may occur because some of the heat is taken to evaporate the mixed oil B50 which is more difficult to evaporate due to its stronger molecular attractive forces. The temperature drop to the poor mixture region was steeper in the attractive magnetic field which means the flame was less stable in the poor mixture than the magnetic field repels or without magnetic field flame. This 
shows that the molecule plays a very important role in helping the magnetic field in stabilizing combustion.

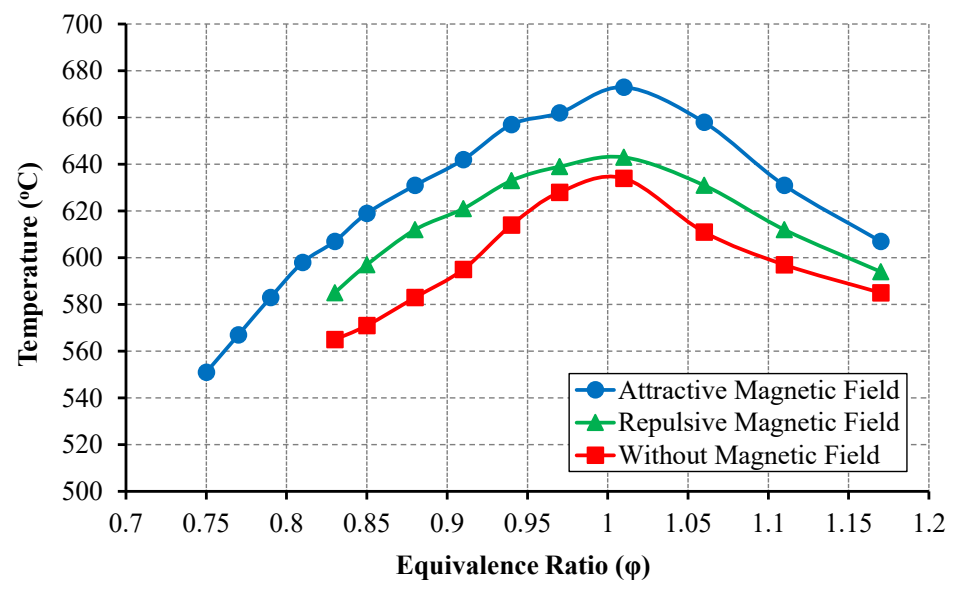

Fig. 6. The flame temperature of the vegetable oil B50 mixture toward its equivalent ratio at various magnetic field orientations and without a magnetic field

\section{4. Flame height at various equivalence ratios and magnetic field directions}

Fig. 7 shows the flame height of the premixed combustion of the coconut oil mixture and the distance B50 at various polar orientations of the magnetic field. A flame without a magnetic field was higher than aflame with a magnetic field of attraction and repulsion.

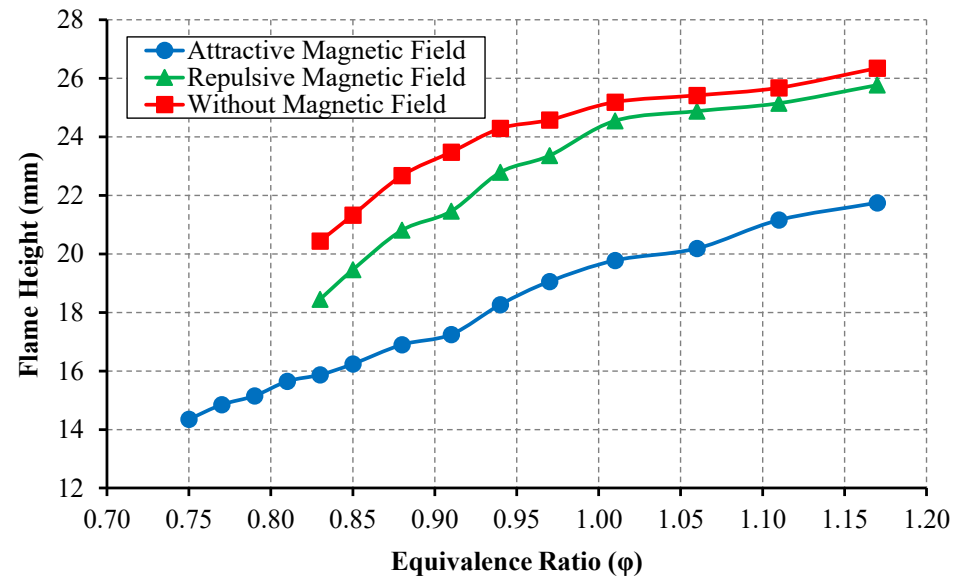

Fig. 7. Flame height of vegetable oil mixture B50 toward its equivalence ratio at various magnetic field orientations and without magnetic field

This indicates that a flame without a magnetic field is less stable than aflame with a magnetic field of attraction and repulsion because a higher one indicates that the flame tends to be less stable. After all, it experiences a greater stretch. The magnetic field exerts a greater influence on shortening the flame in the attractive and repulsive magnetic field. This occurs because the magnetic field makes the electrons more energetic thus the increase in reaction speed can compensate for the diffusion rate (Fig. 5).

\section{Discussion of experimental results}

From some previous research results, it is known that the magnetic field has a major role in the combustion reaction process [20-23]. The first role is that the magnetic field can change the spin of hydrogen protons in the fuel from para to ortho [20-23]. Higher polarity in coconut attracts stronger electrons so it becomes less mobile in coconut oil thus the spin of hydrogen is para. By giving a magnetic field, the proton spin on coconut can change from para to ortho with weaker 
bonds thus the combustion reaction can take place faster. The change from para to ortho is more evident in coconut where laminar burning velocity increases higher because of its stronger electric polarity than jatropha $(\mathbf{F i g} . \mathbf{4 , 5})[20]$. The second role of magnets is to attract paramagnetic molecules which in the case of combustion are oxygen and reject diamagnetic molecules which in this case are products in the form of $\mathrm{H}_{2} \mathrm{O}$ which carry heat. The third magnetic field strength affects the magnetic poles of electrons in molecular bonds, which means that they affect the spin electrons in molecules. With a faster spinning electron due to magnetic field, electrons become more energetic. This is evident from the increase in laminar burning velocity from burning coconut oil and jatropha (Fig. 4, 5). The magnetic field attracts paramagnetic molecules, which in terms of combustion is oxygen, and repels diamagnetic molecules, which in this case is a product in the form of $\mathrm{H}_{2} \mathrm{O}$ which carries heat (Fig. 8).
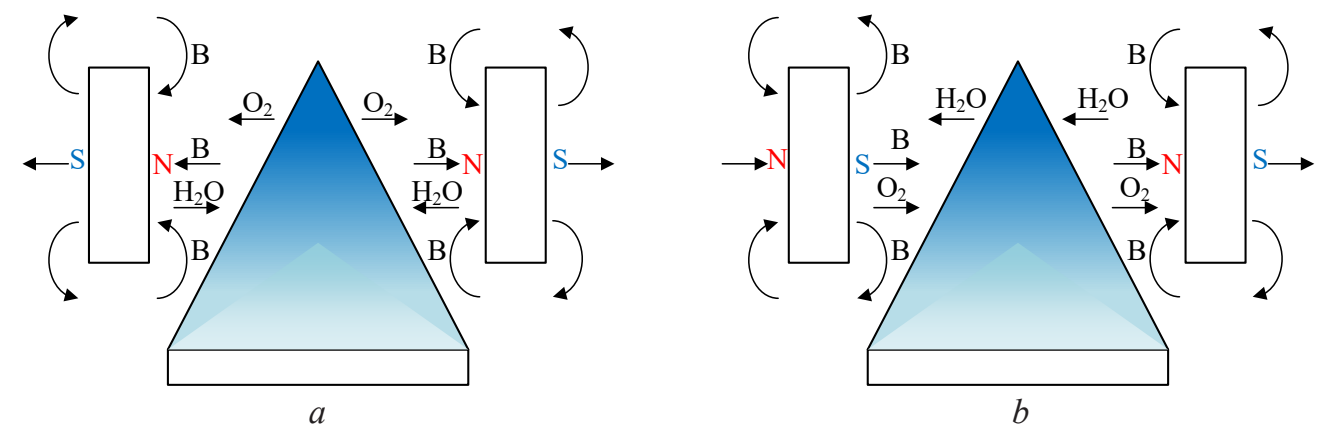

Fig. 8. The role of magnetic field orientation on:

$a$ - paramagnetic $\mathrm{O}_{2} ; b$ - diamagnetic $\mathrm{H}_{2} \mathrm{O}$ in combustion product

The fuel here is a mixture of vegetable oil B50 while the heat was carried by $\mathrm{H}_{2} \mathrm{O}$. The control of these three components, namely $\mathrm{O}_{2}$ withdrawal, $\mathrm{H}_{2} \mathrm{O}$ rejection, and changes in electron and proton spin will determine the combustion process whether it becomes stable, efficient, and low emission or vice versa. The equilibrium between these two events, the proton and electron spin strengthening, and the induction of $\mathrm{O}_{2}$ and $\mathrm{H}_{2} \mathrm{O}$ determine the stability of the premixed combustion of vegetable oils, determined by the orientation of the magnetic field. The exact combination of these two will determine the combustion quality.

However, this study still has shortcomings related to the number and type of vegetable oil and the intensity of the magnetic field that is not large. This is possible, the reduction in plantation land so affects the amount of vegetable oil production in Indonesia tends to decrease, and the low strength of the magnetic field intensity affects the strength of the small characteristic of combustion. This study also cannot project how the fuel, volumetric and thermal efficiency will be in motorized vehicles. So it is necessary to do research that is more focused on its application to engines for all types of vegetable oil, both pure and its derivatives, and the strength of the magnetic field intensity. So that let's obtain several data for progress in the transportation sector.

\section{Conclusions}

The strength of the magnetic field increases the laminar flame speed of the vegetable oil B50 mixture through its role in increasing electron spin and changing the spin of the hydrogen protons in the fuel.

The magnetic field, in addition to accelerating the rate of combustion reactions through the organizing and strengthening of the spin of electrons and protons, also stirs the flame through the induction of $\mathrm{O}_{2}$ and $\mathrm{H}_{2} \mathrm{O}$. The right combination of field strength and magnetic field variation determines the quality of combustion.

\section{Acknowledgment}

I would love to dedicate my special and deep gratitude to the Mechanical Engineering Department and Faculty of Engineering, Universitas Maarif Hasyim Latif Sidoarjo. 


\section{References}

[1] Lin, J.-J., Chen, Y.-W. (2017). Production of biodiesel by transesterification of Jatropha oil with microwave heating. Journal of the Taiwan Institute of Chemical Engineers, 75, 43-50. doi: https://doi.org/10.1016/j.jtice.2017.03.034

[2] Buosi, G. M., da Silva, E. T., Spacino, K., Silva, L. R. C., Ferreira, B. A. D., Borsato, D. (2016). Oxidative stability of biodiesel from soybean oil: Comparison between synthetic and natural antioxidants. Fuel, 181, 759-764. doi: https://doi.org/10.1016/ j.fuel.2016.05.056

[3] Zakaria, R., Harvey, A. P. (2012). Direct production of biodiesel from rapeseed by reactive extraction/in situ transesterification. Fuel Processing Technology, 102, 53-60. doi: https://doi.org/10.1016/j.fuproc.2012.04.026

[4] Nautiyal, P., Subramanian, K. A., Dastidar, M. G. (2014). Production and characterization of biodiesel from algae. Fuel Processing Technology, 120, 79-88. doi: https://doi.org/10.1016/j.fuproc.2013.12.003

[5] Hong, I. K., Lee, J. R., Lee, S. B. (2015). Fuel properties of canola oil and lard biodiesel blends: Higher heating value, oxidative stability, and kinematic viscosity. Journal of Industrial and Engineering Chemistry, 22, 335-340. doi: https://doi.org/10.1016/ j.jiec.2014.07.027

[6] Rakopoulos, D. C., Rakopoulos, C. D., Kyritsis, D. C. (2016). Butanol or DEE blends with either straight vegetable oil or biodiesel excluding fossil fuel: Comparative effects on diesel engine combustion attributes, cyclic variability and regulated emissions trade-off. Energy, 115, 314-325. doi: https://doi.org/10.1016/j.energy.2016.09.022

[7] Wei, S., He, C., Liu, X., Song, Z., Zhao, X. (2019). Numerical Analysis of the Effects of Swirl Ratio on the Performance of Diesel Engine Fueled with N-Butanol-Diesel Blends. Journal of Energy Engineering, 145(3), 04019005. doi: https://doi.org/ 10.1061/(asce)ey.1943-7897.0000600

[8] Rakopoulos, D. C., Rakopoulos, C. D., Giakoumis, E. G., Dimaratos, A. M., Founti, M. A. (2011). Comparative environmental behavior of bus engine operating on blends of diesel fuel with four straight vegetable oils of Greek origin: Sunflower, cottonseed, corn and olive. Fuel, 90 (11), 3439-3446. doi: https://doi.org/10.1016/j.fuel.2011.06.009

[9] Leenus Jesu Martin, M., Edwin Geo, V., Kingsly Jeba Singh, D., Nagalingam, B. (2012). A comparative analysis of different methods to improve the performance of cotton seed oil fuelled diesel engine. Fuel, 102, 372-378. doi: https://doi.org/10.1016/ j.fuel.2012.06.049

[10] Daho, T., Vaitilingom, G., Ouiminga, S. K., Piriou, B., Zongo, A. S., Ouoba, S., Koulidiati, J. (2013). Influence of engine load and fuel droplet size on performance of a CI engine fueled with cottonseed oil and its blends with diesel fuel. Applied Energy, 111, 1046-1053. doi: https://doi.org/10.1016/j.apenergy.2013.05.059

[11] Savariraj, S., Ganapathy, T., Saravanan, C. G. (2012). Performance and emission characteristics of diesel engine using high-viscous vegetable oil. International Journal of Ambient Energy, 33 (4), 193-203. doi: https://doi.org/10.1080/01430750.2012.709356

[12] San José Alonso, J. F., Romero-Ávila, C., San José Hernández, L. M., Awf, A.-K. (2012). Characterising biofuels and selecting the most appropriate burner for their combustion. Fuel Processing Technology, 103, 39-44. doi: https://doi.org/10.1016/j.fuproc.2011.07.023

[13] Rath, S., Kumar, S., Singh, R. K. (2011). Performance and emission analysis of blends of karanja methyl ester with diesel in a compression ignition engine. International Journal of Ambient Energy, 32 (3), 161-166. doi: https://oi.org/10.1080/ 01430750.2011 .619885

[14] Bharathiraja, M., Manikalithas, P., Venkatachalam, R. (2014). Experimental investigation of performance and emission characteristics of non-preheated and preheated Karanja oil blend as alternate fuel in the compression-ignition engine. International Journal of Ambient Energy, 35 (2), 71-79. doi: https://doi.org/10.1080/01430750.2013.770796

[15] Qi, D. H., Lee, C. F., Jia, C. C., Wang, P. P., Wu, S. T. (2014). Experimental investigations of combustion and emission characteristics of rapeseed oil-diesel blends in a two cylinder agricultural diesel engine. Energy Conversion and Management, 77, 227-232. doi: https://doi.org/10.1016/j.enconman.2013.09.023

[16] Chang, Y.-C., Lee, W.-J., Wang, L.-C., Yang, H.-H., Cheng, M.-T., Lu, J.-H. et. al. (2014). Effects of waste cooking oil-based biodiesel on the toxic organic pollutant emissions from a diesel engine. Applied Energy, 113, 631-638. doi: https://doi.org/ 10.1016/j.apenergy.2013.08.005

[17] Popovicheva, O. B., Kireeva, E. D., Steiner, S., Rothen-Rutishauser, B., Persiantseva, N. M., Timofeev, M. A. et. al. (2014). Microstructure and Chemical Composition of Diesel and Biodiesel Particle Exhaust. Aerosol and Air Quality Research, 14 (5), 1392-1401. doi: https://doi.org/10.4209/aaqr.2013.11.0336

[18] Mwangi, J. K., Lee, W.-J., Whang, L.-M., Wu, T. S., Chen, W.-H., Chang, J.-S. et. al. (2015). Microalgae Oil: Algae Cultivation and Harvest, Algae Residue Torrefaction and Diesel Engine Emissions Tests. Aerosol and Air Quality Research, 15 (1), 81-98. doi: https://doi.org/10.4209/aaqr.2014.10.0268

[19] Che Mat, S., Idroas, M. Y., Hamid, M. F., Zainal, Z. A. (2018). Performance and emissions of straight vegetable oils and its blends as a fuel in diesel engine: A review. Renewable and Sustainable Energy Reviews, 82, 808-823. doi: https://doi.org/ 10.1016/j.rser.2017.09.080 
[20] Faris, A. S., Al-Naseri, S. K., Jamal, N., Isse, R., Abed, M., Fouad, Z. et. al. (2012). Effects of Magnetic Field on Fuel Consumption and Exhaust Emissions in Two-Stroke Engine. Energy Procedia, 18, 327-338. doi: https://doi.org/10.1016/ j.egypro.2012.05.044

[21] Patel, P. M., Rathod, G. P., Patel, T. M. (2014). Effect of Magnetic Field on Performance and Emission of Single Cylinder Four Stroke Diesel Engine. IOSR Journal of Engineering, 4 (5), 28-34. doi: https://doi.org/10.9790/3021-04552834

[22] Habbo, A. R. A., Khalil, R. A., Hammoodi, H. S. (2011). Effect of Magnetizing the Fuel on the Performance of an S. I. Engine. AL-Rafdain Engineering Journal (AREJ), 19 (6), 84-90. doi: https://doi.org/10.33899/rengj.2011.26611

[23] Ugare, V., Dhoble, A., Lutade, S., Mudafale, K. (2014). Performance of Internal Combustion (CI) Engine Under the Influence of Stong Permanent Magnetic Field. International Conference on Advances in Engineering \& Technology - 2014 (ICAET-2014), 11-17. Available at: http://iosrjournals.org/iosr-jmce/papers/ICAET-2014/me/volume-5/3.pdf

[24] Perdana, D., Wardana, I. N. G., Yuliati, L., Hamidi, N. (2018). The role of fatty acid structure in various pure vegetable oils on flame characteristics and stability behavior for industrial furnace. Eastern-European Journal of Enterprise Technologies, 5 (8 (95)), 65-75. doi: https://doi.org/10.15587/1729-4061.2018.144243

Received date 25.02.2021

Accepted date 14.07.2021

Published date 13.09.2021
(C) The Author(s) 2021

This is an open access article under the Creative Commons CC BY license

How to cite: Perdana, D., Adiwidodo, S., Choifin, M., Winarko, W. A. (2021). The effect of magnetic field variations in a mixture of coconut oil and jatropha on flame stability and characteristics on the premixed combustion. EUREKA: Physics and Engineering, 5, 13-22. doi: https://doi.org/10.21303/2461-4262.2021.001996 